\title{
A Proposed Functional Analysis of Transmission Prevention Behaviors for a Respiratory Virus (SARS-CoV-2)
}

\author{
Lesley A. Shawler ${ }^{1}$ (D) Bryan J. Blair ${ }^{2}$ (D)
}

Accepted: 24 March 2021 / Published online: 13 September 2021

(C) This is a U.S. government work and not under copyright protection in the U.S.; foreign copyright protection may apply 2021

\begin{abstract}
The coronavirus (SARS-CoV-2) pandemic has had a global impact on lives everywhere and has led to the disruption of, and interference with, virtually every aspect of life. In response, leading experts, political leaders, doctors, and scientists have released guidelines that attempt to prevent and mitigate the exponential rate of infection. The response to these safety recommendations has produced tremendous behavior variability as a society. Although a plethora of factors are likely relevant, a more complete analysis of human behavior during this time might help explain this disparity. The principles of applied behavior analysis allow for a functional analysis of an individual's use of transmission prevention behaviors (TPBs) during the SARS-CoV-2 pandemic. Thus, the purpose of this discussion is to provide a conceptual analysis for some possible explanations for why individuals might or might not engage in virus TPBs, as well as some recommendations to help combat the current pandemic, as well as those in the future.
\end{abstract}

Keywords applied behavior analysis · COVID-19 - disease prevention · public health · SARS-CoV-2

The current global novel coronavirus (severe acute respiratory syndrome coronavirus 2 or SARS-CoV-2, referred to as coronavirus for the remainder of this article) pandemic and

Lesley A. Shawler

shawler@kennedykrieger.org

1 Department of Behavioral Psychology, Kennedy Krieger Institute and Johns Hopkins University School of Medicine, 9810 Patuxent Woods Dr., Ste. C., Columbia, MD 21046, USA

2 School of Education, Long Island University, Orangeburg, NY, USA 
resultant disease (COVID-19) have created a profound and unprecedented disruption throughout society (Ferguson et al., 2020; West et al., 2020). As of March 2021, there were over $120,000,000$ confirmed cases globally, with over 29,000,000 confirmed cases and over 537,000 deaths in the United States alone ${ }^{1}$ (Dong et al., 2020). As a result of the rapid growth and vast propagation of coronavirus and the prevalence of the resultant disease, in March 2020, the World Health Organization (WHO) declared a global pandemic (Cucinotta \& Vanell, 2020). Millions of people have since been infected, with vulnerable members of the population susceptible to serious illness and even death (Emanuel et al., 2020; U.S. Centers for Disease Control and Prevention, 2021). Many have also suffered significant collateral effects from the pandemic, including financial loss and social and physical isolation from family, friends, and coworkers. Students of all ages lost access to traditional forms of in-person instruction and social contact with peers (Chu et al., 2020; Viner et al., 2020).

In response, the $\mathrm{CDC}$ continues to develop and disseminate guidelines to help prevent the transmission of coronavirus and the subsequent development of individual cases of COVID-19 (CDC, 2021). These guidelines include the following individual primary transmission prevention behaviors (TPBs): wash your hands frequently with soap and water for at least $20 \mathrm{~s}$ or use a hand sanitizer with at least $60 \%$ alcohol; avoid touching your eyes, nose, and mouth with dirty hands; stay home and away from others when you are exhibiting symptoms of COVID-19; maintain at least $2 \mathrm{~m}$ distance from others when in public or if they are sick; avoid gathering in large groups (varies based on state regulations); cover your mouth and nose with a cloth covering when outside the home; cover your mouth and nose when you cough or sneeze by using a tissue or the inside of your sleeve, then wash your hands immediately; be alert for symptoms (especially if you need to go into the community); and clean and disinfect commonly touched surfaces daily (CDC, 2021). Research has emphasized the importance of adhering to safety recommendations for transmission prevention (Inglesby, 2020), with emerging data demonstrating how public-health interventions have been associated with decreases in COVID-19 cases in Wuhan, China, since the start of the pandemic (Pan et al., 2020).

At first glance, emitting TPBs appears to be logical, reasonable, sensible, and relatively low effort. Meta-analyses have reported the substantial impact of hand hygiene on the prevention of influenza transmission (Saunders-Hastings et al., 2017; Tooher et al., 2013). Similarly, research on wearing face coverings and engaging in proper hand hygiene has demonstrated promising results for infection prevention for influenza and other coronaviruses (Howard et al., 2021; Leung et al., 2020). Although the long-term effects of other TPBs such as social distancing and staying home indefinitely are harder to measure, some emerging evidence supports the claim that these types of interventions are necessary to prevent the exponential growth of coronavirus (Courtemanche et al., 2020). However, even with direct manipulation of some recommendations, many variables contribute to virus transmission. The direct effects of each TPB are, therefore, difficult to isolate and measure. Despite promising findings from meta-analyses, society should interpret these results with caution as they were based on seasonal influenza cases and not coronavirus. Research should evaluate the various modalities of transmission, individual TPBs, their effects on infection rates, and

$\overline{{ }^{1} \text { Data are current as of March 17, }} 2021$. 
possible differences between virus transmission across seasons and other pandemics (Saunders-Hastings et al., 2017).

Although many people have adhered to these safety restrictions, a large percentage of the population ignores these recommendations (Harper et al., 2020). Initially, some people refused to follow social distance recommendations, even going so far as to throw "coronavirus" parties, breaking state or county regulations limiting gatherings to a small size (Socolovsky, 2020). The specific factors that contribute to variations in complying with regulations are not fully understood. This phenomenon is consistent with previous pandemics in which research reported mixed understanding of TPBs during the H1N1 influenza pandemic (Tooher et al., 2013). In the current era of social media and 24-hr news, it is improbable that many people are unaware of the current TPB recommendations. Nevertheless, many media outlets continue to report individuals congregating in large gatherings, attempting to reopen businesses, traveling, and moving throughout densely populated cities without face coverings. Most recently, even with many universities canceling spring break to discourage travel and large gatherings, students were reported to continue to travel and assemble anyway, as they could complete their online courses from any location (Nadworny, 2021). In many documented cases, people have forcefully resisted following TPB recommendations due to political, religious, philosophical, and various other beliefs (Barua et al., 2020).

\section{Current State of Coronavirus in the United States}

The United States has continued to maintain the highest coronavirus infection and death rates as compared to other countries (Dong et al., 2020). Responses to the pandemic and guidelines have been inconsistent across states, municipalities, and individuals. Some have immediately adopted recommendations, by sheltering in place, wearing face coverings, and only leaving the home for emergencies or essential needs. Others have rejected social-distancing and face-covering measures and continued to socialize in groups and venture out in public as usual. For example, many people refuse to wear face coverings, even to the point of being dismissed from stores, having physical altercations with strangers, or being forcefully removed from airplanes (Associated Press, 2020). Still others are in the middle, inconsistently or arbitrarily choosing which TPBs to follow. The evidence remains clear, however, that engaging in empirically supported TPBs will result in lower disease transmission rates (Gravina et al., 2020; Howard et al., 2021). Given this wide variability of behavior, it is not surprising that the models of infection and death rates continue to predict stark increases over time (Emanuel et al., 2020). Behavior analysts are uniquely poised to assess the possible environmental variables that might contribute to low rates of TPB compliance. It is necessary to analyze the relevant controlling contingencies for each individual. As such, the purpose of the following discussion is to propose a paradigm for the analysis of TPBs and competing behaviors that might lead to lower rates of viral transmission, disease, and death within a population. We aim to identify, analyze, and discuss possible barriers to the widespread acceptance and demonstration of TPBs and provide potential 
explanations and recommendations for the extreme fluctuations across the adherence to TPBs during the coronavirus pandemic.

\section{Applied Behavior Analysis and Public Health}

Applied behavior analysis (ABA) is based on the principles of respondent and operant conditioning (Skinner, 1953) and refers to the scientific study of socially significant and large-scale behavior change (Baer et al., 1968, 1987; Normand \& Kohn, 2013). Hovell et al. (1986) proposed how ABA could improve public health and preventative measures (e.g., obesity, smoking, transmission of infections or viruses, sudden unexpected infant death $)^{2}$ using antecedent interventions (e.g., prompts and decreased response effort; Elba \& Ivy, 2018), motivation, stimulus control (e.g., Elba \& Ivy, 2018), differential reinforcement to increase desirable behaviors (e.g., Bowman et al., 2019; Yokley \& Glenwick, 1984), and punishment to reduce or minimize high-risk behaviors that lead to infection, injury, or death. Eckholm (1977) asserted, "It is important to note that the prevention of infectious disease has been accomplished predominantly by environmental interventions, rather than medical treatments" (p. 295). These and similar techniques can be employed and followed with behavior change, and ABA should be a leader in developing effective preventative methods within the public-health sector. West et al. (2020) emphasized the importance of identifying the factors that relate to the rate of infection to control transmission, mitigate harm, and develop new patterns of behavior in preparation for new pandemics.

A growing body of published research on the application of behavior-analytic technologies treating public-health behaviors currently exists. However, behavior analysts have focused less on applying these principles to disease prevention. Some research has incorporated ABA into more organizational behavior change, such as increasing handwashing or hand sanitizing among employees and students by providing frequent performance feedback, education with written materials, and reminders (e.g., Bordlein, 2020; Bowman et al., 2019; Choi et al., 2018; Fournier \& Berry, 2012; Gravina et al., 2020; Naikoba \& Hayward, 2001). Thus, we propose similar practices to increase compliance with other disease prevention strategies (for a review of behavioral interventions in the workplace, see Cambridge Center for Behavioral Studies [CCBS], , 2020, or Gravina et al., 2020).

\section{Behavioral Principles That Account for Low Rates of TPBs}

A thorough and individualized functional analysis could clarify some of the possible controlling variables for guideline compliance, as well as some potential explanations for engaging in competing, but less safe, behaviors. We will review some fundamental principles of behavior, including reinforcement, stimulus control, motivating operations, rule following, and emergent responding, to fully conceptualize a behavior

\footnotetext{
${ }^{2}$ For more examples on how ABA has been used to treat public health crises, see the Journal of Applied Behavior Analysis (2020), Issue 4, special series, and Perspectives on Behavior Science (2019), Issue 3, addiction treatment.
} 
analytic account of TPBs and alternative behaviors. Although a full analysis of each of these concepts is outside the scope of this discussion, we provide a preliminary review to stimulate and generate some possible ideas for improving society's adherence to TPBs during the current or any subsequent pandemic.

\section{Antecedent Interventions}

\section{Stimulus Control}

Humans respond to a variety of internal and external environmental stimuli in a myriad of ways (Michael, 2004). Some stimuli come to control responding due to histories of exposure to reinforcing contingencies. For example, in the grocery store, visual symbols on the floor could serve as a prompt to indicate where to stand in order to maintain social distance from others (U.S. Food and Drug Administration, 2020) based on past consequences (Skinner, 1953). If a stimulus precedes a behavior that is not reinforced, then that stimulus (and others similar to it) will most likely not exert much control over future responses. For instance, a sign might properly function to remind employees to clean their work areas, provided that similar signs have resulted in employers reinforcing those behaviors. Thus, a failure to reinforce such behaviors or an inconsistent requirement to adhere to these stimuli would likely result in these behaviors decreasing over time. Other variables such as motivational levels or the degree of response effort required to emit the response might also impact stimulus control.

\section{Motivating Operations}

Motivating operations (MOs; Michael, 1982) are directly related to the likelihood that a response might occur. A consequence can only change behavior if the organism is momentarily deprived of the reinforcer and that corresponding reinforcer becomes more valuable and behaviors to obtain it increase. TPBs and unsafe behaviors are under the same fundamental control of MOs as all other behaviors. For many people who are staying home quarantined for an extended period (i.e., deprivation from social interaction), seeing friends and having social interactions likely will become more valuable (Chu et al., 2020). This increased deprivation might result in eventually planning outings or events to see friends, although initially, alternatives such as video chats or phone calls might have been sufficient.

The current era of social media and access to technology has provided many opportunities to substitute for in-person interactions during these social distancing times. Families, schools, and communities have moved to virtual events and celebrations, livestreaming, or more easily accessible forms of entertainment. Although initially these events might provide some acceptable alternatives, the longer the period of deprivation, the stronger the reinforcement value of social interactions becomes. The motivation to engage in these types of interactions and ultimately pursue them will likely increase over time until deprivation wanes. Motivative variables can also affect the potency of reinforcers such that more robust reinforcers will likely produce more behaviors to access them. For example, in the United States, there were increases in COVID-19 cases during the holiday season (Stone, 2020). Many people had refrained 
from large gatherings and social interactions throughout much of the year. However, the typical traditions related to holidays and events such as Thanksgiving, compounded with periods of deprivation, led many people to disregard safety precautions in order to spend time with family. Consequently, hospitals started reporting large influxes of COVID-19 cases that were likely a direct result of gatherings during the holidays (Stone, 2020).

\section{Response Effort}

Research has shown that simply manipulating items to decrease response effort can increase desirable behaviors (Friman \& Poling, 1995). As effort increases, responding decreases (Mowrer \& Jones, 1943), extinction occurs more quickly (Mowrer \& Jones, 1943), responding to escape difficult situations is more likely (Miller, 1968a, 1968b), and people prefer low-effort responding compared to high-effort responding (Perone \& Baron, 1980). For example, many stores and restaurants have started providing a curbside pickup option to encourage social distancing and minimize physical interactions inside by decreasing response effort and allowing customers to order on mobile applications (Kelso, 2020). However, response effort alone might not impact behavior change on a consistent level. Even with the reduced effort level to engage in TPBs, other competing reinforcers, such as needing a warm place to exercise or preferring to physically see items prior to buying, might influence one's likelihood of engaging in TPBs.

\section{Reinforcement, Extinction, Punishment, and Competing Responses}

Providing reinforcement for adaptive behaviors while discontinuing reinforcement for maladaptive behaviors (i.e., extinction) has a robust history of effective behavior change across a diverse range of behaviors and populations (Cooper et al., 2020). Therefore, consistent reinforcement should be delivered for engaging in TPBs; for example, one university paid college students to stay home instead of traveling over spring break (Nadworny, 2021). Some individuals also have longer histories of reinforcement for not adhering to health guidelines and therefore might continue to engage in generally unhealthy or unsafe behaviors. Basic human-operant experiments have demonstrated that humans will allocate responding in a way that results in the greatest amount of reinforcement. (e.g., Baum, 1979). However, reinforcers can be fleeting (i.e., MOs) and will vary based on an individual's current motivative levels. This could partially explain why some people might be more or less likely to engage in TPBs.

Punishment is a ubiquitous process that decreases responding over time (Vollmer, 2002). Punishment could explain why some are not engaging in TPBs. For example, wearing a face covering has become a controversial, politicized recommendation. Some people refuse to wear one because they find it uncomfortable to keep on or view it as infringing on their human rights. Both of these events might be considered aversive and inherently decrease the likelihood of wearing face coverings in the future. Punishment procedures could also be a strategy to minimize or reduce unsafe or harmful behaviors leading to the transmission of coronavirus. Some community settings have adopted policies in which people will be asked to leave if they are not wearing face coverings 
(Associated Press, 2020; Zarroli, 2020). Inconsistent punishment practices currently exist partly due to political conflict or ineffective punishers.

Differential reinforcement includes reinforcing a desired response while withholding reinforcement for other less preferred behaviors (Cooper et al., 2020). Behaviors that continue to contact reinforcement will maintain over time, whereas behaviors that do not will decrease. People who stay home and socialize using videoconferencing platforms as opposed to in person might initially contact high levels of reinforcement. However, as time passes, because in-person social contact is occurring at very low rates, along with prolonged periods of screen time for other activities (e.g., Zoom fatigue; Robinson, 2020), staying home might occur less frequently and in-person social interaction may increase. Over time, people might gradually start planning outings with friends and family and stay home less. Reinforcement rates will also fluctuate based on the effort level required to complete that activity (e.g., visiting a neighbor vs. a friend who lives 30 min away). People who demonstrate noncompliance with TPBs are likely engaging in alternative behaviors that are more reinforcing, more immediate, and possibly easier to complete (e.g., seeing a friend now or waiting a few months and communicating only through video).

\section{Generalized Imitation and Modeling}

Observing others engage in relevant behaviors while contacting reinforcement for those behaviors can result in the observer engaging in similar behaviors (Bandura, 1965). Modeling can occur at a national level but can also occur in any relevant setting, including from supervisors in a workplace (Gravina et al., 2020) or other community members. A lack of modeling of engagement in TPBs can also influence the occurrence of safe behaviors. Former President Donald Trump and certain state and local officials refused to wear a face covering, which might have provided tacit approvals that face coverings are not required or their usefulness is unfounded (Graham et al., 2020). Inconsistent modeling across leaders and experts can also lead to general societal confusion, reluctance, or resistance to engage in proper TPBs.

\section{Verbal Behavior, Rule-Governed Behavior, and Function-Altering Effects}

Verbal behavior is reinforced through the mediation of another person who responds because of a conditioning history for reinforcing a speaker's behavior (Skinner, 1957). Skinner (1957) described verbal discriminative stimuli (e.g., rules, signs) that can control both verbal and nonverbal behaviors through a history of differential reinforcement. Skinner $(1957,1966,1969)$ also referred to behavior as rule governed if it occurred in response to contact with a certain verbal stimulus (i.e., rule), describing a functional relation but no actual exposure to the contingency directly. Humans have a unique ability to behave in accordance with rules even when they are inconsistent with direct contingencies (Weiner, 1964, 1969). CDC and state guidelines can be conceived of as verbal rules that could strengthen the evocative functions of previously established stimuli or create new relations between those stimuli and behaviors 
(Schlinger \& Blakely, 1987). For example, upon hearing the rule "Wear a mask when you enter the store to protect others from illness," many people will put on a face covering, despite no previous consequences of seeing others become ill in this context.

Skinner (1957) suggested that the clarity of the controlling verbal stimuli, the conditioning history of the listener, and the "prestige" of the speaker might all affect a listener's response to rules (p. 365). This lack of clarity might also reduce the general prestige of the speaker(s), or rule providers, and affect the probability that the listener will follow current and future guidelines. For example, information related to the prevention of the transmission of coronavirus has been inconsistent and unclear (The Lancet Editors, 2020), and as the number of cases grew exponentially, these recommendations might have become more and more difficult to understand, believe, and subsequently follow. This confusion and lack of conceptual and practical coherence are further exacerbated when elected officials, scientists, health directors, doctors, researchers, and epidemiologists present completely contradictory advice or behave inconsistently themselves (Buttigieg, 2020; McCoy et al., 2018; New England Journal of Medicine Editors, 2020). Health-policy leaders initially recommended that people not wear face coverings, then weeks later those same leaders advocated that people should wear face coverings. Such misinformation and confusion can lead to inaccurate reporting, which might result in reinforcement from certain audiences (Guerin, 1992). Contradictory information might have also been one of the catalysts for former President Trump to constantly denounce scientists and other infectious disease experts throughout the pandemic (Shabad \& Alba, 2020). Although verbal behavior might be used to describe inaccurate contingencies (i.e., false information), the social contingencies that follow such information are valid and can reinforce its occurrence, as well as control responding in accordance with this verbal behavior (Guerin, 1992).

Research has examined three possible factors that contribute to rule adherence $\left(\right.$ Torneke, 2010) ${ }^{3}$. First, individuals whose behavioral history includes reinforcement for general obedience (i.e., pliance) might be more likely to follow rules (e.g., Berry et al., 1992). Individuals who are less likely to adhere to TPB regulations from experts, scientists, or other leaders likely have histories of reinforcement for not complying with rules from authority figures, possibly due to mistrust or potential punishment contingencies from the past. Second, some might follow rules related to tracking, defined as an individual learning through direct contingencies related to compliance (Zettle \& Hayes, 1982). For some, previously following the rules of washing hands frequently or wearing a face covering in public has led to maintained good health or avoidance of illness over time (i.e., negative reinforcement). By contrast, someone who does not frequently adhere to TPB rules yet still avoids becoming ill might be less likely to adopt these new behaviors due to separate reinforcement contingencies (possibly their own self-generated rules). Last, a rule that features formative or motivative augmentals (Barnes-Holmes et al., 2001; Torneke, 2010) in addition to pliance or tracking can influence the reinforcing value of the consequences that are specified in the rule, increasing the probability that one will follow it (Stapleton, 2020). A formative augmental establishes something new as reinforcing (e.g., a face covering) based on

\footnotetext{
${ }^{3}$ Relational frame theory is an additional way that behavior analysts can conceptualize TPBs with possible solutions; however, this discussion is beyond the scope of this article.
} 
the likelihood of reinforcing consequences provided in the rule (e.g., "To keep yourself and others safe, you should wear a face covering"; Torneke, 2010). In a motivative augmental, one could attempt to align a rule with an individual's preexisting values by telling a family member to "shelter in place for the next 2 weeks, if you want to be able to see the baby after she is born." However, this rule might be less likely to be complied with if seeing the newborn baby was not valued or if other reinforcers were more immediate or powerful.

Another potential cause of nonadherence to rules could be due to ineffective contingencies that do not necessarily control behavior (Catania, 1979). This noncompliance might be due to the contingency being too delayed, not observable, or too difficult to follow. The absence of direct contingencies or clear instructions for specific behaviors can sometimes lead to self-generated or derived rules, which might then control behavior (Leander et al., 1968; Lippman \& Meyer, 1967; Ninness \& Ninness, 1999). Moreover, rules that specify contingencies that seem to result in improbable outcomes are also less likely to be followed (Malott, 1988). The less likely it seems that one might become infected (based on media predictions, statistics, one's own opinions, etc.), the more likely someone might ignore safety recommendations.

\section{Consequence Discounting and Certainty}

A functional analysis of TPBs becomes more complicated when the consequences for responding are delayed or uncertain for a substantial period. The asymptomatic transmission of coronavirus has been considered an "invisible threat" given that it is generally unobservable and the source of infection is not always known. This uncertainty, along with the possibility of a delayed incubation period, might result in an infection that is difficult to attribute to a particular behavior. For example, a multistate telephone survey of 350 adult inpatients and outpatients who had tested positive for COVID-19 reported that $54 \%$ of patients could not identify how or where they were exposed to coronavirus (Tenforde et al., 2020). Failing to identify this information accurately could likely influence the probability of engaging in the exposure behavior again in the future (Critchfield \& Kollins, 2001).

Temporal discounting suggests that as the amount of time increases between a response and a consequence, the less potent the consequence becomes. Engaging in TPBs could also be conceptualized within this same framework (Fig. 1). For example, a possible functional reinforcer for staying home during a pandemic might include the prevention of the transmission of the virus. This prevention is a temporally remote contingency; thus it most likely has relatively weak control over staying home in the future. In comparison, going to the corner coffee shop to meet a friend during a pandemic, though very unsafe, could be immediately reinforced with social attention. Fortunately, delay discounting research has found that humans are more likely to demonstrate self-control (e.g., stay home during a pandemic), as the perceived severity of the medical condition increases (Weatherly \& Terrell, 2014). This finding might help to explain why some are more likely to follow recommendations (i.e., consider the virus to be a large threat), whereas others are less likely (i.e., do not consider the virus to be dangerous).

Probability discounting occurs when the value of an outcome decreases as the likelihood of the outcome decreases (Kaplan et al., 2016; Madden \& Bickel, 2010). 


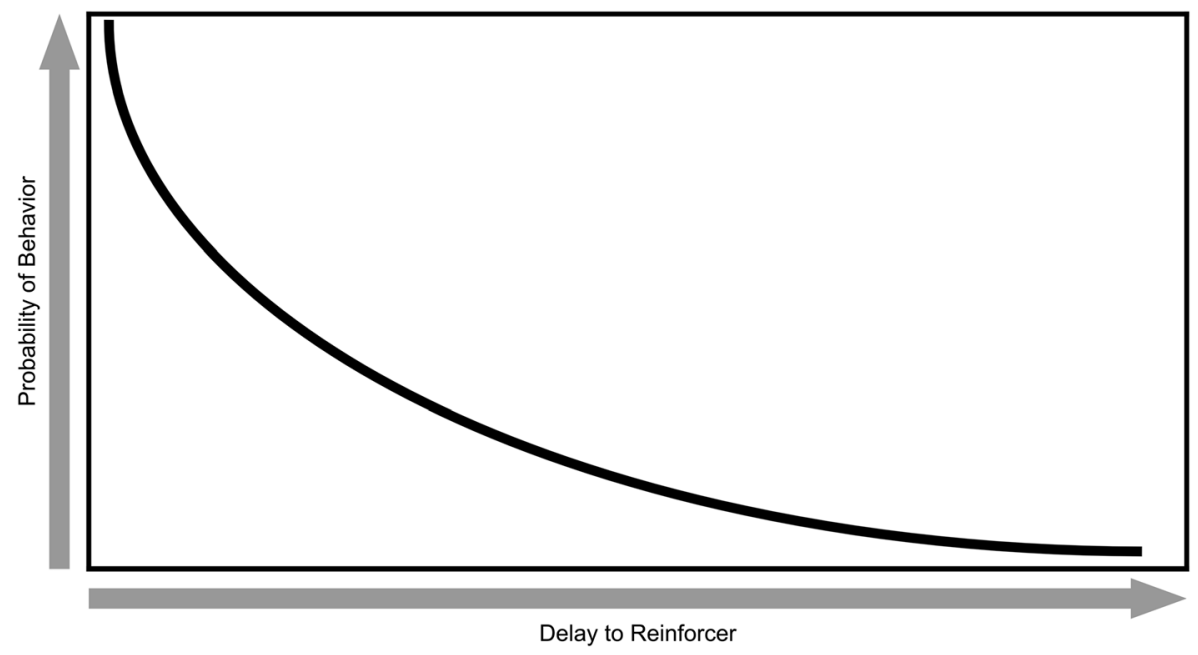

Fig. 1. Temporal Discounting of Reinforcement Potency

Thus, the less likely something might occur, the more likely the consequence will be discounted. Discounting research has found that participants tend to discount the consequences of medical decisions less (e.g., Weatherly \& Terrell, 2014) when the likelihood of becoming ill increases (Kaplan et al., 2016) or the severity of illness is higher (Camargo et al., 2021). Guerin's (1992) discussion of "virtual worlds" and constructed misinformation that becomes reinforced through certain audiences might explain how one can perceive the severity of the virus and their corresponding actions. Recent COVID-19 research has found that an increased number of risky choices reported on a questionnaire can predict low compliance with TPBs such as mask wearing or social distancing (Byrne et al., 2020).

An applied paradigm for the analysis of both TPBs and competing behaviors is the Positive Immediate Certain/Negative Immediate Certain (PIC/NIC) Consequence Assessment (Daniels \& Daniels, 2006). The PIC/NIC analysis categorizes functional consequences for behaviors as either positive or negative, ${ }^{4}$ immediate or future, and certain or uncertain (Table 1). The PIC/NIC analysis suggests that the probabilities of responding are linked to either a temporal dimension or the probabilistic quality of the reinforcer. In the previous scenario, if a person stays home (Fig. 2), the consequence of being lonely is negative (aversive), immediate, and certain (NIC). In contrast, if a person goes out and disregards social-distancing recommendations, the positive (appetitive) consequence of social connection is both immediate and certain (PIC). The TPB of staying home, although definitely positive (appetitive), is also more distant (i.e., future effect) and somewhat uncertain given all other behaviors that could be cooccurring. The effects of going to the coffee shop are negative (aversive), equally distant, and uncertain. Both the temporal discounting and PIC/NIC analyses suggest that it might be challenging to ensure that some people stay home without additional

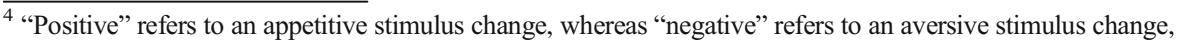
and neither refer to the addition/removal of a stimulus.
} 
Table 1. PIC/NIC Analyses of Transmission Prevention Behaviors With Consequences of Remaining Not Infected and/or Not Infecting Others

\begin{tabular}{|c|c|c|c|}
\hline \multirow[t]{2}{*}{ Behavior } & \multicolumn{3}{|c|}{ Consequence is. } \\
\hline & $\begin{array}{l}\text { Positive } \\
\text { /negative }\end{array}$ & $\begin{array}{l}\text { Immediate } \\
\text { /future }\end{array}$ & $\begin{array}{l}\text { Certain } \\
\text { /uncertain }\end{array}$ \\
\hline \multicolumn{4}{|l|}{ Primary } \\
\hline Wear face covering & Positive & Future & Uncertain \\
\hline Stay home when symptomatic & Positive & Future & Certain \\
\hline Stay home (in general) & Positive & Future & Certain \\
\hline Minimize group interaction & Positive & Future & Uncertain \\
\hline Maintain 6 feet of distance in public or when others are symptomatic & Positive & Future & Uncertain \\
\hline Avoid poorly ventilated indoor spaces & Positive & Future & Uncertain \\
\hline Wash hands and use hand sanitizer & Positive & Immediate & Uncertain \\
\hline Disinfect surfaces & Positive & Immediate & Uncertain \\
\hline Cough/sneeze into elbows/shoulders & Positive & Immediate & Uncertain \\
\hline Engage incompatible behaviors for touching face & Positive & Immediate & Uncertain \\
\hline Monitor symptoms & Positive & Future & Uncertain \\
\hline \multicolumn{4}{|l|}{ Secondary } \\
\hline Eat healthily and stay hydrated & Positive & Future & Uncertain \\
\hline Exercise & Positive & Future & Uncertain \\
\hline Research and analyze media reports and data & Positive & Future & Uncertain \\
\hline
\end{tabular}



Fig. 2. PIC/NIC Analysis of Wearing a Face Covering. Note. $\mathrm{PIC} / \mathrm{NIC}=$ positive immediate certain / negative immediate certain. 
immediate and certain reinforcement (e.g., alternative social connections or competing monetary payments).

\section{Emergent Responding and Transfer/Transformation of Function}

A common human behavioral phenomenon involves the development of derived (i.e., untrained) relations that can emerge as a result of the direct training of other arbitrary stimuli (Sidman, 1994). A robust empirical literature base suggests that emergent responding (e.g., derived relational responding, emergent verbal behavior, and emergent rule generation) can account for the observed transfer of stimulus function among physically dissimilar stimuli (Dymond \& Rehfeldt, 2000; Sidman, 1994) or between seemingly unrelated words and phrases (Grow \& Kodak, 2010), resulting in classes of stimuli becoming functionally substitutable. In other words, stimuli can acquire similar functional control over responding without direct training even when those stimuli appear to be only arbitrarily (i.e., not physically) related.

During the pandemic, society has observed behaviors that initially seemed unexpected and/or incompatible with the prevailing stimulus conditions. However, an analysis of verbal behavior and emergent relational responding might explain some of these responses that competed with TPBs. For example, former President Trump incorrectly told Americans numerous times that the virus is similar to the common $\mathrm{flu}^{5}$ (Hensley, 2020). As a result, given many Americans' history with influenza, a subset of people might have behaved in similar ways as they would with the flu. They neither substantially changed their behavior nor followed coronavirus-specific recommendations for TPBs. In this case, the transfer of function for the presence of coronavirus due to a history of experience with influenza was not coherent with facts and reality, resulting in possibly unnecessary higher rates of unsafe behaviors.

Another example of the unintended transfer of function might have been observed at the start of the pandemic with reports of hoarding essential items such as toilet paper, water, bread, and so forth (Chu et al., 2020; Labad et al., 2021). Toilet paper might seem to be an odd item to stockpile given that COVID-19 symptoms do not generally consist of bowel or gastrointestinal issues (CDC, 2021). In most situations, essential items are only purchased when needed and have specific evocative functions that do not change very much over time. However, given previous learning histories during natural disasters or social crises (possibly through externally provided rules, selfgenerated rules, or exposure to direct contingencies), people might have learned that they should rush to the store to purchase things like toilet paper. Thus, when individuals learned that coronavirus might have similar effects on civil and commercial structures and systems (i.e., a directly taught intraverbal between natural disaster and coronavirus with no direct evidence of its accuracy), the emergent response of hoarding toilet paper (Figure 3) might increase. The function of seeing essential items at a store transformed from a stimulus that controlled a certain stable behavior (i.e., buying only when necessary) to an item that now evoked stockpiling. This conceptualization might explain why some people engaged in risky behavior such as leaving their homes to purchase toilet paper, as the reinforcement value for this item was momentarily, but

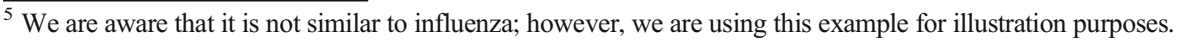




\section{Before Coronavirus}

Seeing essential supplies resulted in purchasing what one needed. During natural disasters or crises, people stocked up. The novel word "coronavirus" most likely had no effect on the function of seeing essential supplies in stores.

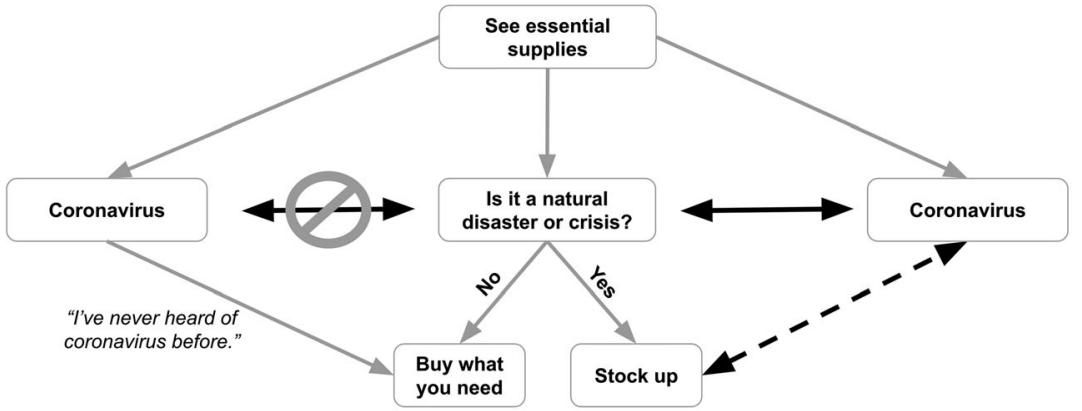

During Coronavirus

Seeing essential supplies resulted in a greater probability of stocking up because of the possible learned relation between the no-longer-novel word "coronavirus" and "natural disaster" or "crisis".

Fig. 3. Diagram of a Possible Explanation for Inaccurate Emergent Responding

inaccurately, high (Labad et al., 2021). Once the toilet paper was purchased, this might have resulted in higher rates of certain TPBs, like staying home and social distancing, because the seemingly derived fear of running out of items was eliminated.

\section{Examples of Multiply Controlled TPBs}

TPBs are likely controlled by multiple momentary environmental stimuli, idiosyncratic motivation, and historical stimulus condition changes. These variables often dynamically enhance or mitigate behavioral control and probability across contexts. Momentary MOs influence differential reinforcement and maintenance (Langthorne \& McGill, 2009), rules can reduce the strength of contingencies of reinforcement (Ayllon \& Azrin, 1964), and transformation of function and emergent responding can inadvertently override accurate and relevant verbal behavior (Friman et al., 1998). For example, the result of constant exposure to the media and hearing how death and infection rates continue to spike could lead to the development of "anxiety" regarding coronavirus and COVID-19 and lead to some irrational or unfounded verbal behavior or actions.

\section{Some Contextual Variables That Control TPBs}

A general analysis of pandemics might suggest some other contextual explanations for certain behaviors. In the United States, variables that control TPBs might include the infrequency of pandemics; individual variables might include education level, socioeconomic status, and culture. Given the infrequency of pandemics in the United States, there have been minimal contingencies in place for responding to viruses of this magnitude, which leads to individuals resorting to behaving in accordance with previous histories of reinforcement or punishment for TPBs. Due to these infrequent direct contingencies, many of the current recommendations are strictly rule-governed 
behaviors. As described previously, many variables can directly influence an individual's likelihood of responding to rules. In contrast, some countries, such as those in Southeast Asia, have been deemed centers for emerging infectious diseases, with pandemic potential (Coker et al., 2011). Mask wearing for the prevention of viruses has become a much more common practice and is often considered hygiene etiquette (Wong et al., 2020). Conversely, wearing face coverings has been very rare across other countries in which pandemics are infrequent.

Additional variables such as education level, socioeconomic status, and culture could contribute to the probability of engaging in TPBs (Tooher et al., 2013). In a systematic review, Tooher et al. (2013) evaluated community response to the H1N1 pandemic and found that individuals with more education and higher socioeconomic status were more likely to be aware of pandemic information and follow recommendations. Individuals with less education could have more difficulty discriminating legitimate factual information compared to propaganda or other misinformation. Especially in the age of social media, when information can be shared freely without any fact-checking, consumers would need to know how to access peer-reviewed research to contact empirically supported information. The level of response effort to thoroughly analyze and validate information is extremely high, and it is often easier to quickly read and believe immediately available misinformation, resulting in wide dissemination that can supplant facts (i.e., "virtual worlds"; Guerin, 1992).

Another general factor might be how familiar a person is with visual, numerical, and statistical presentations of data, such as testing, case positivity, and death rates. Research has shown that graphical displays can communicate health risks, support informed medical decision making, and promote risk-avoidant behaviors (GarciaRetamero \& Cokely, 2017; Okan et al., 2019). However, graphical representations of virus transmission and death rates are potentially confusing, as they are often depicted in a variety of uncommon and possibly unfamiliar formats and presentations (e.g., exponential, logarithmic, cumulative, geographic). At a minimum, these data require certain specific, but perhaps infrequent, numerical, logical, and analytical skills in order for them to be interpreted quickly and correctly. Moreover, interpretation and analysis of data and graphs might also require some minimal formal and systematic education or experience in order to account for all potential confounding variables or logical flaws affecting the data. For example, the exponential nature of the number of increasing cases might seem alarming, leading to increases in fear, anxiety, and doubt or to the spread of misinformation. However, an important consideration is whether the increase is due to the growing number of coronavirus tests being administered simultaneously. Conversely, someone less familiar with visual analysis might see a decrease in the graphed rate of cases and deaths, represented by a plateau, and not attribute this flattening of a curve to the occurrence of effective TPBs or other policies and interventions. Misinterpreting these data can impact how individuals behave during the pandemic and whether they will follow TPBs in the future.

Families with lower incomes might also be required to work long hours, leaving little time for following the news. These individuals could also have limited access to the internet, TV, or smartphones, increasing the response effort to access and monitor the continually evolving preventative recommendations. Low-income neighborhoods and work settings are less likely to allow for privileges such as working from home or social distancing, potentially increasing exposure to or spread of coronavirus (Yancy, 
2020). Similarly, those with poor socioeconomic status might be less likely to call out sick from work due to the potential loss of wages, thereby exposing others to infection (Gravina et al., 2020). Research has suggested that behaviors that result in higher rates of reinforcement (e.g., money) will more likely occur, as opposed to punished behaviors (e.g., loss of money, potential to be fired). Similarly, TPBs that are less expensive (e.g., washing hands, buying items online, using curbside pickup), as opposed to more expensive (e.g., buying multiple face coverings, staying home and missing work), might be more likely to occur (Saunders-Hastings et al., 2017).

Cultural variables might also impact awareness and adherence to TPBs during global pandemics (Tooher et al., 2013). Nonnative English speakers might be less likely to follow the news or updates due to language barriers or a lack of understanding of the severity of the crisis (Quinn \& Kumar, 2014). Ensuring proper understanding of evolving updates will require high levels of response effort to learn English or find people who are willing to interpret. Local governments might struggle to communicate effectively with certain groups within their communities, thus requiring extra response effort from consumers to access health care or other resources (Quinn \& Kumar, 2014). Maintaining cultural traditions such as family gatherings/ celebrations or weekly religious services could also pose a barrier to adhering to TPBs if those events are not easily modified for safety or the competing reinforcers to stay safe are not potent enough.

\section{Recommendations}

True experimental functional analyses could identify potential functions of individual behaviors leading to highly effective interventions. In some settings, these types of analyses might be challenging (Hanley et al., 2003) and sometimes inconclusive (Hagopian et al., 2013), particularly with complex behaviors with longer experiential histories and varying stimulus conditions. However, in order to complete an accurate analysis and develop appropriate functional replacement behaviors, behavior analysts must continue to assess the possible controlling variables for harmful or risky behaviors. Even in the absence of traditional systematic and individualized functional analyses, it is possible to formulate some general, but functionally targeted interventions, including some of the following (Table 2):

1. Antecedent interventions: Proactive strategies should be employed to help minimize the spread of coronavirus. Such strategies could include temperature checks at every establishment prior to entering, analyzing wastewater for coronavirus in sewage systems to help detect possible outbreaks and then mandating social distancing or staying at home in the affected areas, and using cell phone data to monitor the potential for large group activity. Other countries are developing technological methods to improve coronavirus monitoring, and the United States should follow models that have more successfully responded to and combated the virus' spread.

a. Stimulus control: Agencies can provide specific examples and encourage the use of antecedent interventions, including visual supports, written reminders, cues, and 


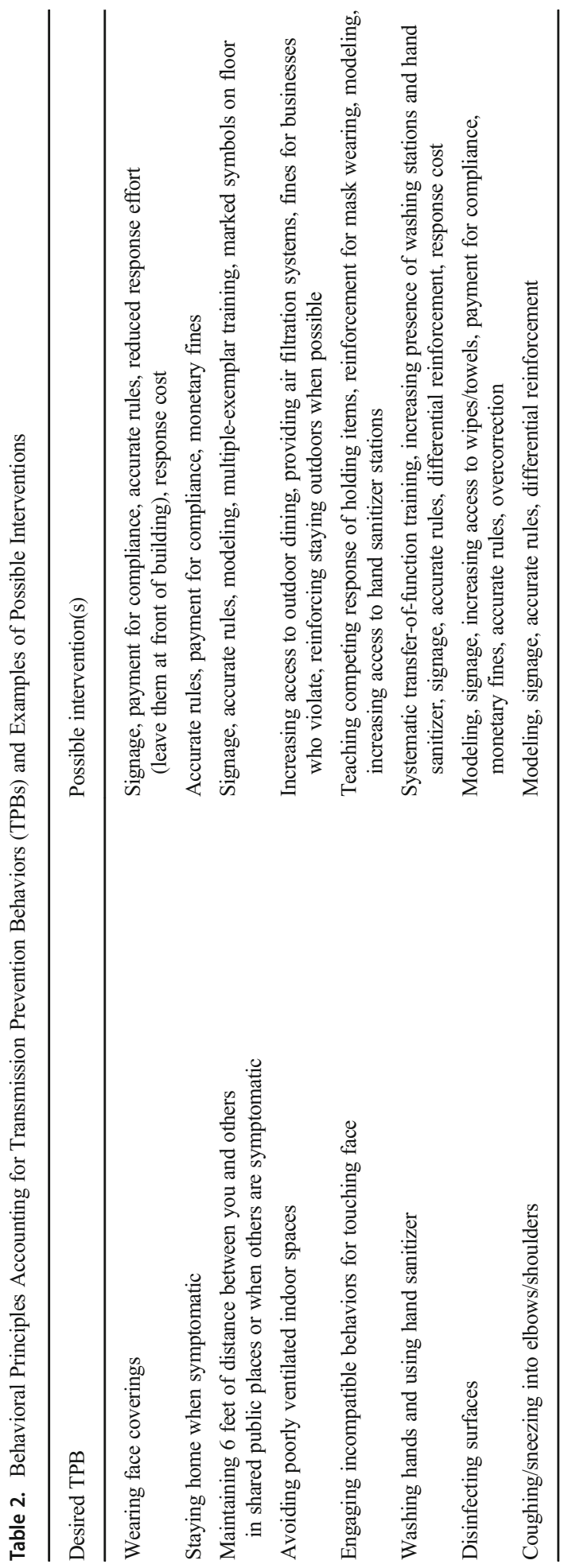


prompts, to improve adherence to TPBs (e.g., CCBS, 2020; Felde et al., 2020; Gravina et al., 2020). Some specific examples include written instructions and pictures for wearing a face covering in public places, signs providing alternative methods to greet others without touching, widely available handwashing stations or hand sanitizer, free/low-cost face coverings that are present at entrances to any public building, disinfectant wipes near high-touch areas, contactless transactions, markers on the ground for where to stand in stores/where to sit on the beach, and public postings in person or on social media (e.g., Camden \& Ludwig, 2013). Electronic health attestation systems (Dubuque et al., 2020) can collect information without physical contact (minimizing in-person interactions) on potential coronavirus exposure and can serve as a proactive agreement that both parties will abide by. As these types of strategies become more abundant, reinforcement systems should be developed to reinforce individuals' accurately responding to these stimuli and strategies. Punishment procedures should also be created for when individuals engage in unsafe behaviors (see specific reinforcement recommendations in what follows).

b. MOs: In order to reduce the level of deprivation of social contact, agencies and institutions can consider strongly encouraging people to socially connect using remote technologies like videoconferencing for both personal and professional purposes (e.g., virtual game nights with staff, coffee meetings). Large livestreamed events like concerts, performances, sporting events, and so forth can minimize some deprivation from social activity. When possible, hold events outdoors but still accommodate for social distancing, wearing masks, and providing frequent handwashing stations. Promoting fun (and safe) outdoor activities such as small group exercising, drive-by social events, and socially distanced neighborhood parties can provide opportunities for social interactions. Consider ensuring all basic human needs are met by providing free or less expensive food and medication and easy and inexpensive access to essential items through in-home deliveries or curbside pickup. Cities and counties could provide some safe in-person options such as alternating days in which small gatherings could occur in large indoor venues or outside with a maximum number of people allowed.

c. Response effort: Simple strategies to reduce response effort in these contexts (e.g., health insurance companies mailing each member health care packages including sanitizer, disinfectant wipes, face coverings, thermometers, etc.; having face coverings and sanitizing wipes available at the door, frequent handwashing stations in public, vending machines with masks and hand sanitizer for a low cost placed throughout buildings and community settings) might help increase the likelihood that desirable behaviors occur (e.g., Felde et al., 2020; Friman \& Poling, 1995). Continuing to allow curbside pickup at restaurants and stores, while minimizing or eliminating delivery or shipping costs, can encourage these types of practices. Technology advancements can be used to alert communities when there are outbreaks in certain areas (e.g., an emergency cell phone alert for outbreaks) so as to minimize exposure, as well as to improve contact tracing and other tracking systems using low-effort applications. Additionally, decreasing response effort combined with other strategies such as reinforcement systems for using handsanitizing stations or disinfecting one's work area could potentially increase safety behaviors. 
2. Reinforcement, extinction, and punishment: Identify potent reinforcers to be delivered contingent on desirable behaviors such as TPBs (e.g., Tiger et al., 2008). Use differential, immediate, and certain intermittent reinforcement for engaging in safe behavior. Agencies should strongly consider direct payments or rebates for engaging in TPBs, such as staying home, wearing face coverings, complying with signs or rules, washing hands in the community, standing on visual markers, using contactless delivery or transactions, or using mobile/computer contact/infection tracing applications (Dubuque et al., 2020). Consider reinforcement systems such as large lotteries (raffles), monetary rewards, paid time off, donated prizes, and discounts for complying with various policies (e.g., Bowman et al., 2019; Yokley \& Glenwick, 1984). These types of systems could be conducted in work settings, in the community, and through government programs. Initially, reinforcers might have to be delivered immediately (e.g., money) and following every response, but over time they can be faded to less frequent and more delayed presentations (e.g., schedules of reinforcement, conditioned reinforcers) to maintain appropriate responding. Organizations should differentially reinforce adhering to sick-policy guidelines (i.e., providing monetary compensation for calling out sick when appropriate as opposed to trying to work while ill). Organizations and schools should remove incentives for "perfect attendance," as these types of contingencies can promote noncompliance to TPBs (Gravina et al., 2020). Finally, contingency contracts could be developed to increase the number of responsibilities or time that safe behaviors should occur prior to reinforcement, thereby creating more sustainable procedures.

a. Competing responses: One of the $\mathrm{CDC}$ recommendations to reduce virus transmission includes minimizing the frequency of touching one's face. Research on habit-reversal training has effectively shown that teaching an incompatible response helps to reduce repetitive behaviors (e.g., Azrin \& Nunn, 1973; Heinicke et al., 2020). As such, habit-reversal training procedures can teach people to become "aware" of when they touch their face and to then engage in incompatible responses, such as sitting on their hands or making a fist. By minimizing the frequency of face touching, this TPB can help to decrease virus transmission. However, this type of procedure requires trained professionals to initially teach the competitive responses, along with maintenance from a social network that can help remind or praise the individual when the relevant behavior occurs (Heinicke et al., 2020).

b. Punishment: After effective punishers are identified, they can be delivered contingent on unsafe behaviors such as entering a store without a mask on or standing too close to someone in line. Consider response-cost procedures such as fines or loss of other privileges or responsibilities for engaging in unsafe behaviors. In the event of repeat offenders, or if dangerous behavior becomes difficult to control, we suggest monetary fines, similar to parking tickets and other civil fines. Other punishment procedures such as overcorrection (e.g., not cleaning up after eating could result in an employee cleaning an entire kitchen) could also be considered. Importantly, punishment procedures should be used only after all other antecedent, reinforcement, and other nonaversive interventions have been unsuccessful. They should also be combined with less restrictive strategies for best results. 
c. An important consideration for optimal outcomes is someone must be designated to provide consistent consequences. Once individuals observe that they do not have to comply with TPBs, they will likely stop responding or respond inconsistently. If individuals observe others receiving reinforcement or punishment for responding appropriately or inappropriately to rules or policies, they will be more likely to modify their behavior accordingly.

3. Generalized imitation and modeling: A recent review highlighted the impact of how modeling can be used to promote and teach desirable behaviors, such as teaching young children to wash their hands to ensure proper hygiene (Jess \& Dozier, 2020). Modeling and imitation might also facilitate contact with naturally occurring forms of reinforcement or punishment, which might affect whether a behavior is likely to occur again in the future (Bandura, 1965). Former President Trump consistently refused to wear a face covering, discouraged others from wearing one, and mocked highly visible people who chose to model this behavior (e.g., candidate and now current President Joe Biden). His influential behavior might have had detrimental effects on his followers and those who emulated his unsafe behavior, possibly contributing to the spread of COVID-19 (Graham et al., 2020). Instead, we need strong, consistent models of powerful government officials and experts complying with CDC recommendations. These models would likely have a trickle-down effect in which national, regional, state, and local leaders would be more likely to imitate and encourage others to respond similarly.

4. Verbal behavior, rules, and consequence discounting: All institutions, individual leaders, elected officials, medical experts, and scientists must strive to substantially improve the accuracy and consistency of their collective recommendations for the use of TPBs with supporting evidence, when possible. This must include dissemination of information and preventative recommendations in many languages while remaining sensitive to specific cultural considerations when relevant (e.g., cultural gatherings, traditions). Consistent methods of communication could be created, such as cell phone alerts or social media forums that include proper enforcement and monitoring of misinformation. Leaders should also suggest and provide immediate and certain opportunities for alternative and safe reinforcing activities that would allow for social interactions but still adhere to TPB guidelines (e.g., small gatherings at the park, birthday/graduation parades, virtual ceremonies or audiences). Given the variability in society's response to verbal instructions, it is recommended that providing rules should be combined with other strategies with clear consequences (i.e., reinforcement or punishment) to increase the likelihood of compliance (Gravina et al., 2020).

5. Emergent responding and transfer of function: One could create simple training tutorials and activities to facilitate the emergence of untrained responses and transfer of function across stimuli to combat inaccurate transfers that might have already occurred. For example, a simple web-based matching activity (Blair \& Shawler, 2019; Brodsky \& Fienup, 2018) could be created to ensure that accurate relations between and among stimuli (e.g., coronavirus is not the same as influenza) related to coronavirus are trained and tested, including emergent responding.

6. Combinations of strategies: Like any comprehensive function-based behavior analytic intervention, every possible indicated strategy can be used and synthesized with other interventions in order to increase rates of TPBs. Depending on the target 
population, individuals can use many of these suggestions in tandem or conduct systematic/experimental component analyses to determine the efficacy of each procedure.

Overall, more research is needed to evaluate these potential interventions on behavior change. Behavior analysts should conduct small-scale within-subject clinical research, including case studies, on simple behavior analytic interventions focused on the analysis of controlling variables and/or the increase of rates of TPBs. For example, a simple A-B-A-B or multiple-baseline design study could be conducted to determine if the availability of masks or handwashing stations prior to entering buildings increases the rates of mask wearing or handwashing. Behavior analysts should also collaborate with other professionals about incorporating behavior-analytic principles into more mainstream outlets and social issues (e.g., Jarmolowicz et al., 2019).

Behavior analysts can partner with other professionals (e.g., statisticians, epidemiologists, computer programmers, public-health officials) to use their specific research, clinical training, and experience to develop simple, free digital training modules on how to analyze cumulative, rate, and logarithmic/ exponential growth graphs and disseminate the training modules widely. Other countries are currently developing mobile applications to help track coronavirus spread and monitor social distancing and contact tracing. For example, Prem et al. (2020) developed a program in which they could predict the trajectory of possible virus outbreaks and then provide possible solutions for individuals safely returning to work or school in Wuhan, China. Given the narrow scope that behavior analysts often face, partnering with more well-known experts or fields might result in broader dissemination of research and effective strategies.

\section{Concluding Remarks}

Skinner (1987) asked, "Most thoughtful people agree that the world is in serious trouble. . . . Why is more not being done?" (p. 1). That question has remained true since the pandemic started, given the stark reality of the unimaginable and almost incomprehensible damage caused by the dynamic relationship between human behavior and coronavirus. Skinner (1987) further posited that humans should examine their own behavior and the environmental conditions that influence it in order to change. ABA and closely related behavioral technologies have a robust literature base demonstrating how basic principles can be used for large-scale behavior change. Currently, the application and mainstream acceptance of these principles as pragmatic and eminently functional technologies have been disappointingly limited (Dixon et al., 2018). The continued investigation of best practices in the area of public health must continue through systematic research and exploration (Normand \& Kohn, 2013), particularly given the recent coronavirus outbreak and its collateral effects on society. The implementation of behavioral principles like reinforcement, stimulus control, rule following, emergent responding, and antecedent manipulations 
could be widely applied to increase the rates of healthy and safe behaviors and to replace alternative risky and unsafe behaviors. Moreover, functional analyses of TPBs might help arrange environmental conditions that promote such safe behaviors at the individual level. In order to ultimately succeed, behavior analysts must strive for the dissemination of the science of ABA on a larger global scale to attempt to improve problems of social significance (Baer et al., 1968 , 1987). It is only then that we might be able to more confidently say that we, as behavioral scientists, are attempting to truly save the world.

Availability of data and material Not applicable.

Code availability Not applicable.

Authors' contributions Both authors participated in the conceptualization, development, writing, and revision of the manuscript.

\section{Declarations}

Ethics approval Not applicable.

Consent to participate Not applicable.

Consent for publication Not applicable.

Conflicts of interest/competing interests The authors declare no conflicts of interest.

\section{References}

Associated Press. (2020). Man removed from flight after fight with fellow passenger over refusal to wear mask. CBS News. https:/www.cbsnews.com/news/man-removed-from-flight-after-fight-with-fellowpassenger-over-refusal-to-wear-mask/. Accessed 21 Mar 2021.

Ayllon, T., \& Azrin, N. H. (1964). Reinforcement and instructions with mental patients. Journal of Experimental Analysis of Behavior, 7(4), 327-331. https://doi.org/10.1901/jeab.1964.7-327

Azrin, N. H., \& Nunn, R. G. (1973). Habit-reversal: A method of eliminating nervous habits and tics. Behaviour Research and Theory, 11(4), 619-628. https://doi.org/10.1016/0005-7967(73)90119-8

Baer, D. M., Wolf, M. M., \& Risley, T. R. (1968). Some current dimensions of applied behavior analysis. Journal of Applied Behavior Analysis, 1(1), 91-97. https://doi.org/10.1901/jaba.1968.1-91

Baer, D. M., Wolf, M. M., \& Risley, T. R. (1987). Some still current dimensions of applied behavior analysis. Journal of Applied Behavior Analysis, 20(4), 313-327. https://doi.org/10.1901/jaba.1987.20-313

Bandura, A. (1965). Influence of models' reinforcement contingencies on the acquisition of imitative responses. Journal of Personality and Social Psychology, 1(6), 589-595. https://doi.org/10.1037/ h0022070

Barnes-Holmes, D., O’Hora, D., Roche, B., Hayes, S. C., Bisset, R. T., \& Lyddy, F. (2001). Understanding and verbal regulation. In S. C. Hayes, D. Barnes-Holmes, \& B. Roche (Eds.), Relational frame theory: A post-Skinnerian account of human language and cognition (pp. 103-119). Plenum.

Barua, Z., Barua, S., Aktar, S., Kabir, N., \& Li, M. (2020). Effects of misinformation on COVID-19 individual responses and recommendations for resilience of disastrous consequences of misinformation. Progress in Disaster Science, 8, 100-119. https://doi.org/10.1016/j.pdisas.2020.100119

Baum, W. M. (1979). Matching, undermatching, and overmatching in studies of choice. Journal of the Experimental Analysis of Behavior, 32(2), 269-281. https://doi.org/10.1901/jeab.1979.32-269 
Berry, T. D., Geller, E. S., Calef, R. S., \& Calef, R. A. (1992). Moderating effects of social assistance on verbal interventions to promote safety belt use: An analysis of weak plys. Environment and Behavior, 24, 653-669. https://doi.org/10.1177/0013916592245005

Blair, B. J., \& Shawler, L. A. (2019). Developing and implementing emergent responding training systems with available and low-cost computer-based learning tools: Some best practices and a tutorial. Behavior Analysis in Practice, 1-12. https://doi.org/10.1007/s40617-019-00405-x

Bordlein, C. (2020). Promoting hand sanitizer use in a university cafeteria. Behavior and Social Issues, 29, 255-263. https://doi.org/10.1007/s42822-020-00026-y

Bowman, L. G., Hardesty, S. L., Sigurdsson, S. O., McIvor, M., Orchowitz, P. M., Wagner, L. L., \& Hagopian, L. P. (2019). Utilizing group-based contingencies to increase hand washing in a large human service setting. Behavior Analysis in Practice, 12(3), 600-611. https://doi.org/10.1007/2Fs40617-018$00328-\mathrm{z}$

Brodsky, J., \& Fienup, D. M. (2018). Sidman goes to college: A meta-analysis of equivalence-based instruction in higher education. Perspectives on Behavior Science, 41(1), 95-119. https://doi.org/10. 1007/s40614-018-0150-0

Buttigieg, P. (2020). Trust: America’s best chance. Liveright Publishing.

Byrne, K. A., Six, S., Anaraky, R. G., Harris, M. W., \& Winterlind, E. L. (2020). Risk-taking unmasked: Using risky choice and temporal discounting to explain COVID-19 preventative behaviors. PLoS one, 16 (5), e0251073. https://doi.org/10.31234/osf.io/uaqc2

Camargo, J., Passarelli, D. A., de Oliveira, M. A., \& de Rose, J. C. (2021). Probability discounting and adherence to preventative behaviors during the COVID-19 pandemic. PsyArXiv. https://doi.org/10. 31234/osf.io/p4a76

Cambridge Center for Behavioral Studies. (2020). Covid-19, behavioral infection prevention. Retrieved 01/25/ 21, from https://behavior.org/wp-content/uploads/2020/05/CCBSCOVIDSafety.pdf

Camden, M. C., \& Ludwig, T. D. (2013). Absenteeism in health care: Using interlocking behavioral contingency feedback to increase attendance with certified nursing assistants. Journal of Organizational Behavior Management, 33(3), 165-184. https://doi.org/10.1080/01608061.2013.814521

Catania, A. C. (1979). Learning. Prentice Hall.

Centers for Disease Control and Prevention. (2021). Coronavirus. Retrieved 01/15/21, from https://www.cdc. gov/coronavirus/2019-ncov/index.html

Choi, B., Lee, K., Moon, K., \& Oah, S. (2018). A comparison of prompts and feedback for promoting handwashing in university restrooms. Journal of Applied Behavior Analysis, 51(3), 667-674. https://doi. org/10.1002/jaba.467

Chu, I. Y., Alam, P., Larson, H. J., \& Lin, L. (2020). Social consequences of mass quarantine during epidemics: A systematic review with implications for the COVID-19 response. Journal of Travel Medicine, 27(7), 1-14. https://doi.org/10.1093/jtm/taaa192

Coker, R. J., Hunter, B. M., Rudge, J. W., Liverani, M., \& Hanvoravongchai, P. (2011). Emerging infectious diseases in Southeast Asia: Regional challenging to control. The Lancet, 377(9765), 599-609. https://doi. org/10.1016/S0140-6736(10)62004-1

Cooper, J., Heron, T., \& Heward, W. (2020). Applied behavior analysis (3rd ed.). Pearson Education.

Courtemanche, C., Garuccio, J., Le, A., Pinkston, J., \& Yelowitz, A. (2020). Strong social distancing measures in the United States reduced the COVID-19 growth rates. Health Affairs, 39(7), 1237-1246. https://doi. org/10.1377/hlthaff.2020.00608

Critchfield, T. S., \& Kollins, S. H. (2001). Temporal discounting: Basic research and the analysis of socially important behavior. Journal of Applied Behavior Analysis, 34(1), 101-122. https://doi.org/10.1901/jaba. 2001.34-101

Cucinotta, D., \& Vanell, M. (2020). WHO declares COVID-19 a pandemic. Acta Biomedica, 91(1), 157-160. https://doi.org/10.23750/abm.v91i1.9397

Daniels, A. C., \& Daniels, J. E. (2006). Performance management: Changing behavior that drives organizational effectiveness (4th ed.). Performance Management Publications.

Dixon, M. R., Belisle, J., Rehfeldt, R. A., \& Root, W. B. (2018). Why we are still not acting to save the world: The upward challenge of a post-Skinnerian behavior science. Perspectives on Behavior Science, 41(1), 241-267. https://doi.org/10.1007/s40614-018-0162-9

Dong, E., Du, H., \& Gardner, L. (2020). An interactive web-based dashboard to track COVID-19 in real time. The Lancet Infectious Diseases, 20, 533-534. https://doi.org/10.1016/S1473-3099(20)30120-1

Dubuque, E. M., Yingling, M. E., Ranade, E. S., \& Dubuque, M. L. (2020). Creating an automated health attestation system during the COVID-19 pandemic with Microsoft 365. Behavior Analysis in Practice, 13, 799-810. https://doi.org/10.1007/s40617-020-00495-y 
Dymond, S., \& Rehfeldt, R. A. (2000). Understanding complex behavior: The transformation of stimulus functions. The Behavior Analyst, 23(2), 239-254. https://doi.org/10.1007/2FBF03392013

Eckholm, E. P. (1977). The picture of health: Environmental causes of disease. W. W. Norton.

Elba, I., \& Ivy, J. W. (2018). Increasing the post-use cleaning of gym equipment using prompts and increased access to cleaning materials. Behavior Analysis in Practice, 11(4), 390-394. https://doi.org/10.1007/ s40617-018-0217-0

Emanuel, E. J., Persad, G., Upshur, R., Thom, B., Parker, M., Glickman, A., Zhang, C., Boyle, C., Smith, M., \& Phillips, J. P. (2020). Fair allocation of scarce medical resources in the time of Covid-19. The New England Journal of Medicine, 2049-2055. https://doi.org/10.1056/NEJMsb2005114

Felde, A., Haggerty, K., Sleiman, A. A., \& Gravina, N. (2020). Reducing response effort to improve employee preparedness in a human service organization. Behavior Analysis in Practice., 14(1), 198-202. https://doi. org/10.1007/s40617-020-00512-0

Ferguson, N. M., Laydon, D., Nedjati-Gilani, G., Imai, N., Ainslie, K., Baguelin, M., Bhatia, S., Boonyasiri, A., Cucunuba, Z., Cuomo-Dannenburg, G., Dighe, A., Dorigatti, I., Fu, H., Gaythrope, K., Green, W., Hamlet, A., Hinsley, H., Okell, L. C., Elsland, S., Thompson, H. . . Ghani, A. (2020). Report 9: Impact of non-pharmaceutical interventions (NPIs) to reduce COVID-19 mortality and healthcare demand. Imperial College London, 1-20. https://doi.org/10.25561/77482. Retrieved 05/10/20

Fournier, A. K., \& Berry, T. D. (2012). Effects of response cost and socially-assisted interventions on handhygiene behavior of university students. Behavior and Social Issues, 21, 152-164. https://doi.org/10. 5210/bsi.v21i0.3979

Friman, P., Hayes, S. C., \& Wilson, K. G. (1998). Why behavior analysts should study emotion: The example of anxiety. Journal of Applied Behavior Analysis, 31(1), 137-156. https://doi.org/10.1901/jaba.1998.31137

Friman, P., \& Poling, A. (1995). Making life easier with effort: Basic findings and applied research on response effort. Journal of Applied Behavior Analysis, 28(4), 583-590. https://doi.org/10.1901/jaba.1995. 28-583

Garcia-Retamero, R., \& Cokely, E. T. (2017). Designing visual aids that promote risk literacy: A systematic review of health research and evidence-based design heuristics. Human Factors: Journal of the Human Factors and Ergonomics Society, 59(4), 582-627. https://doi.org/10.1177/0018720817690634

Graham, A., Cullen, F. T., Pickett, J. T., Jonson, C. L., Haner, M., \& Sloan, M. M. (2020). Faith in Trump, moral foundations, and social distancing defiance during the coronavirus pandemic. Socius: Sociological Research for a Dynamic World, 6, 1-23. https://doi.org/10.1177/2378023120956815

Gravina, N., Nastasi, J. A., Sleiman, A. A., Matey, N., \& Simmons, D. E. (2020). Behavioral strategies for reducing disease transmission in the workplace. Journal of Applied Behavior Analysis, 53(4), 1935-1954. https://doi.org/10.1002/jaba.779

Grow, L. L., \& Kodak, T. (2010). Recent research on emergent verbal behavior: Clinical applications and future directions. Journal of Applied Behavior Analysis, 43(4), 775-778. https://doi.org/10.1901/jaba. 2010.43-775

Guerin, B. (1992). Behavior analysis and the social construction of knowledge. American Psychologist, 47(11), 1423-1433. https://doi.org/10.1037/0003-066X.47.11.1423

Hagopian, L. P., Rooker, G. W., Jessel, J., \& DeLeon, I. G. (2013). Initial functional analysis outcomes and modifications in pursuit of differentiation: A summary of 176 inpatient cases. Journal of Applied Behavior Analysis, 46(1), 88-100. https://doi.org/10.1002/jaba.25

Hanley, G. P., Iwata, B. A., \& McCord, B. E. (2003). Functional analysis of problem behavior: A review. Journal of Applied Behavior Analysis, 36(2), 147-185. https://doi.org/10.1901/jaba.2003.36-147

Harper, C. A., Satchell, L. P., Fido, D., \& Latzman, R. B. (2020). Functional fear predicts public health compliance in the COVID-19 pandemic. International Journal of Educational Development, 80. https:// doi.org/10.1007/s11469-020-00281-5

Heinicke, M. R., Stiede, J. T., Miltenberger, R. G., \& Woods, D. W. (2020). Reducing risky behavior with habit reversal: A review of behavioral strategies to reduce habitual hand-to-head behavior. Journal of Applied Behavior Analysis, 53(3), 1225-1236. https://doi.org/10.1002/jaba.745

Hensley, S. (2020). Fact check: Trump says 50,000 could die from flu. National Public Radio https://www. npr.org/sections/coronavirus-live-updates/2020/03/23/820435849/fact-check-trump-says-50-000-coulddie-from-flu-so-far-its-half-that

Hovell, M. F., Elder, J. P., Blanchard, J., \& Sallis, J. F. (1986). Behavior analysis and public health perspectives: Combining paradigms to effect prevention. Education and Treatment of Children, 9(4), 287-306 http://www.jstor.org/stable/42898988

Howard, J., Huang, A., Li, Z., Tufekci, Z., Vladimir, Z., Westhuizen, H., Delft, A., Price, A., Fridman, L., Tang, L., Tang, V., Watson, G. L., Bax, C. E., Shaikh, R., Questier, F., Hernandez, D., Chu, L. F., 
Ramirez, C. M., \& Rimoin, A. W. (2021). Face masks against COVID-19: An evidence review. Proceedings of the National Academy of Sciences of the United States of America, 118(4), 1-12. https://doi.org/10.1073/pnas.2014564118

Inglesby, T. V. (2020). Public health measures and the reproduction number of SARS-CoV-2. Journal of the American Medical Association, 323(21), 2186-2187. https://doi.org/10.1001/jama.2020.7878

Jarmolowicz, D. P., Reed, D. D., Bruce, A. S., \& Bruce, J. M. (2019). On the behavioral economics of medication choice: A research story. Behavioural Processes, 165, 66-77. https://doi.org/10.1016/j. beproc.2019.05.019

Jess, R. L., \& Dozier, C. L. (2020). Increasing handwashing in young children: A brief review. Journal of Applied Behavior Analysis, 53(3), 1219-1224. https://doi.org/10.1002/jaba.732

Kaplan, B. A., Reed, D. D., \& Jarmolowicz, D. P. (2016). Effects of episodic future thinking on discounting: Personalized age-progressed pictures improve risky long-term health decisions. Journal of Applied Behavior Analysis, 49(1), 148-169. https://doi.org/10.1002/jaba.277

Kelso, A. (2020). Why curbside pickup is here to stay - even after the pandemic ends. Forbes. Retrieved 01/ 15/21, from https://www.forbes.com/sites/aliciakelso/2020/09/22/restaurant-chains-rushed-to-addcurbside-pickup-during-the-pandemicheres-why-theyll-keep-the-channel-after-it-ends/?sh=6d7c3fc31622

Labad, J., Gonzalez-Rodriguez, A., Cobo, J., Punti, J., \& Farre, J. M. (2021). A systematic review and realist synthesis on toilet paper hoarding: COVID or not COVID, that is the question. PeerJ, 9, e10771. https:// doi.org/10.7717/peerj.10771

The Lancet Editors. (2020). Reviving the US CDC. The Lancet, 395(10236), 1521. https://doi.org/10.1016/ S0140-6736(20)31140-5

Langthorne, P., \& McGill, P. (2009). A tutorial on the concept of the motivating operation and its importance to application. Behavior Analysis in Practice, 2(2), 22-31. https://doi.org/10.1007/BF03391745

Leander, J. D., Lippman, L. G., \& Meyer, M. E. (1968). Fixed interval performance as related to subjects' verbalizations of the reinforcement contingency. The Psychological Record, 18(3), 469-474. https://doi. org/10.1007/BF03393795

Leung, N., Chu, D. K. W., Shiu, E. Y. C., Chan, K., McDevitt, J. J., Hau, B. J. P., Yen, H., Li, Y., Ip, D. K. M., Peiris, J. S. M., Seto, W., Leung, G. M., Milton, D. K., \& Cowling, B. J. (2020). Respiratory virus shedding in exhaled breath and efficacy of face masks. Nature Medicine, 26, 676-680. https://doi.org/10. 1038/s41591-020-0843-2

Lippman, L. G., \& Meyer, M. E. (1967). Fixed interval performance as related to instructions and to subjects' verbalizations of the contingency. Psychonomic Science, 8, 135-136. https://doi.org/10.3758/ BF03331586

Madden, G. J., \& Bickel, W. K. (Eds.). (2010). Impulsivity: The behavioral and neurological science of discounting. American Psychological Association, 243-271. https://doi.org/10.1037/12069-000

Malott, D. (1988). Rule-governed behavior and behavior anthropology. The Behavior Analyst, 11(2), 181203. https://doi.org/10.1007/BF03392471

McCoy, J., Rahman, T., \& Somer, M. (2018). Polarization and the global crisis of democracy: Common pattern, dynamics, and pernicious consequences for democratic politics. American Behavioral Scientist, 62(1), 16-42. https://doi.org/10.1177/0002764218759576

Michael, J. (1982). Distinguishing between discriminative and motivational functions of stimuli. Journal of the Experimental Analysis of Behavior, 37(1), 149-155. https://doi.org/10.1901/jeab.1982.37-149

Michael, J. (2004). Concepts and principles of behavior analysis (2nd ed.). Association for Behavior Analysis International.

Miller, L. K. (1968a). Escape from an effortful situation. Journal of the Experimental Analysis of Behavior, 11(5), 619-627. https://doi.org/10.1901/jeab.1968.11-619

Miller, L. K. (1968b). The effect of response force on avoidance rate. Journal of the Experimental Analysis of Behavior, 11(6), 809-812. https://doi.org/10.1901/jeab.1968.11-809

Mowrer, O. H., \& Jones, H. M. (1943). Extinction and behavior variability as functions of effortfulness of task. Journal of Experimental Psychology, 33(5), 369-386. https://doi.org/10.1037/h0056182

Nadworny, E. (2021). Colleges canceled spring break, but students are traveling anyway. National Public Radio https://www.npr.org/2021/03/16/977568407/colleges-canceled-spring-break-but-students-aretraveling-anyway

Naikoba, S., \& Hayward, A. (2001). The effectiveness of interventions aimed at increasing handwashing in healthcare workers-a systematic review. Journal of Hospital Infection, 47(3), 173-180. https://doi.org/10. 1053/jhin.2000.0882

New England Journal of Medicine Editors. (2020). Dying in a leadership vacuum. The New England Journal of Medicine, 383(15), 1479-1480. https://doi.org/10.1056/NEJMe2029812 
Ninness, H. A. C., \& Ninness, S. K. (1999). Contingencies of superstition: Self-generated rules and responding during second-order response-independent schedules. The Psychological Record, 49, 221243. https://doi.org/10.1007/BF03395318

Normand, M. P., \& Kohn, C. S. (2013). Don't wag the dog: Extending the reach of applied behavior analysis. The Behavior Analyst, 36(1), 109-122. https://doi.org/10.1007/2FBF03392294

Okan, Y., Janssen, E., Galesic, M., \& Waters, E. A. (2019). Using the Short Graph Literacy Scale to predict precursors of health behavior change. Medical Decision Making, 39(3), 183-195. https://doi.org/10.1177/ 0272989X19829728

Pan, A., Liu, L., \& Wang, C. (2020). Association of public health interventions with the epidemiology of the COVID-19 outbreak in Wuhan, China. Journal of American Medical Association, 323(19), 1915-1923. https://doi.org/10.1001/jama.2020.6130

Perone, M., \& Baron, A. (1980). Reinforcement of human observing behavior by a stimulus correlated with extinction or increased effort. Journal of the Experimental Analysis of Behavior, 34(3), 239-261. https:// doi.org/10.1901/jeab.1980.34-239

Prem, K., Liu, Y., Russel, T. W., Kucharski, A. J., Eggo, R. M., \& Davis, N. (2020). The effect of control strategies to reduce social mixing on outcomes of the COVID-19 epidemic in Wuhan, China: A modelling study. The Lancet Public Health, 5(5), 261-270. https://doi.org/10.1016/S2468-2667(20) 30073-6

Quinn, S. C., \& Kumar, S. (2014). Health inequalities and infectious disease epidemics: A challenge for global health security. Biosecurity and Bioterrorism: Biodefense, Strategy, and Science, 12(5), 263-273. https:// doi.org/10.1089/2Fbsp.2014.0032

Robinson, B. (2020). How to mitigate the harmful effects of zoom burnout. Forbes https://www.forbes.com/ sites/bryanrobinson/2020/11/15/how-to-mitigate-the-harmful-effects-of-zoom-burnout/?sh= d1c285944654

Saunders-Hastings, P., Crispo, J. A. G., Sikora, L., \& Krewski, D. (2017). Effectiveness of personal protective measures in reducing pandemic influenza transmission: A systematic review and meta-analysis. Epidemics, 20, 1-20. https://doi.org/10.1016/j.epidem.2017.04.003

Schlinger, H., \& Blakely, E. (1987). Function-altering effects of contingency-specifying stimuli. The Behavior Analyst, 10(1), 41-45. https://doi.org/10.1007/BF03392405

Shabad, R., \& Alba, M. (2020). Trump calls Fauci a "disaster" and says it would be a "bomb" if he fired him. NBC News. Retrieved 03/15/21, from https:/www.nbcnews.com/politics/politics-news/fauci-sayshe-s-not-surprised-trump-contracted-covid-19-n1243857

Sidman, M. (1994). Equivalence relations and behavior: A research story. Authors Cooperative.

Skinner, B. F. (1953). Science and human behavior. The Free Press.

Skinner, B. F. (1957). Verbal behavior. Copley Publishing Group.

Skinner, B. F. (1966). Contingencies of reinforcement in the design of a culture. Behavioral Science, 11(3), 159-166. https://doi.org/10.1002/bs.3830110302

Skinner, B. F. (1969). Contingencies of reinforcement. B. F.

Skinner, B. F. (1987). Whatever happened to psychology as the science of behavior? American Psychologist, 42(8), 780-786. https://doi.org/10.1037/0003-066X.42.8.780

Socolovsky, J. (2020). What to do when people don't practice social distancing. National Public Radio https:// www.npr.org/sections/coronavirus-live-updates/2020/04/28/846684162/what-to-do-when-people-dontpractice-social-distancing

Stapleton, A. (2020). Choosing not to follow the rules. Journal of Contextual Behavior Science, 17, 73-78. https://doi.org/10.1016/j.jcbs.2020.07.002

Stone, W. (2020). Epidemiologists urge a cautious Christmas, after Thanksgiving surge in some states. National Public Radio https://www.npr.org/sections/health-shots/2020/12/21/948809129/ epidemiologists-urge-a-cautious-christmas-after-thanksgiving-surge-in-some-state

Tenforde, M. W., Rose, E. B., Lindsell, C. J., Shapiro, N. I., Files, C., Gibbs, K. W., Prekker, M. E., Steingrub, J. S., Smithline, H. A., Gong, M. N., Aboodi, M. S., Exline, M. C., Henning, D. J., Wilson, J. G., Khan, A., Qadir, N., Stubblefield, W. B., Patel, M. M., Self, W. H., \& Feldstein, L. R. (2020). Characteristics of adult outpatients and inpatients with COVID-19-11 medical centers, United States, March-May 2020. Morbidity and Mortality Weekly Report, 69, 841-846. https://doi.org/10.15585/mmwr.mm6926e3

Tiger, J. H., Hanley, G. P., \& Bruzek, J. (2008). Functional communication training: A review and practical guide. Behavior Analysis in Practice, 1(1), 16-23. https://doi.org/10.1007/BF03391716

Tooher, R., Collins, J. E., Street, J. M., Braunack-Mayer, A., \& Marshall, H. (2013). Community knowledge, behaviours and attitudes about the $2009 \mathrm{H} 1 \mathrm{~N} 1$ influenza pandemic: A systematic review. Influenza, 7(6), 1316-1327. https://doi.org/10.1111/irv.12103 
Torneke, N. (2010). Learning RFT: An introduction to relational frame theory and its clinical application. Context Press.

U.S. Food and Drug Administration. (2020). Best practices for retail food stores, restaurants, and food pick-up/ delivery services during the covid-19 pandemic. Retrieved 03/15/21, from https://www.fda.gov/food/ food-safety-during-emergencies/bestpractices-retail-food-stores-restaurants-and-food-pick-updeliveryservices-during-covid-19

Viner, R. M., Russell, S. J., Croker, H., Packer, J., Ward, J., Stansfield, C., Mytton, O., Bonell, C., \& Booy, R. (2020). School closure and management practices during coronavirus outbreaks including COVID-19: A rapid systematic review. Lancet Child Adolescent Health, 4, 397-404. https://doi.org/10.1016/S23524642(20)30095-X

Vollmer, T. R. (2002). Punishment happens: Some comments on Lerman and Vondran's review. Journal of Applied Behavior Analysis, 35(4), 469-473. https://doi.org/10.1901/jaba.2002.35-469

Weatherly, J. N., \& Terrell, H. K. (2014). Magnitude effects in delay and probability discounting when monetary and medical treatment outcomes are discounted. The Psychological Record, 64, 433-440. https://doi.org/10.1007/s40732-014-0052-9

Weiner, H. (1964). Conditioning history and human fixed-interval performance. Journal of the Experimental Analysis of Behavior, 7, 383-385. https://doi.org/10.1901/jeab.1964.7-383

Weiner, H. (1969). Controlling human fixed-interval performance. Journal of the Experimental Analysis of Behavior, 12, 349-373. https://doi.org/10.1901/jeab.1969.12-349

West, R., Michie, S., Rubin, G. J., \& Amlot, R. (2020). Applying principles of behaviour change to reduce SARS-CoV-2 transmission. Nature Human Behaviour, 4(5), 451-459. https://doi.org/10.1038/s41562020-0887-9

Wong, S. H., Teoh, J. Y. C., Leung, C., Wu, W. K. K., Yip, B. H. K., Wong, M. C. S., \& Hui, D. S. C. (2020). COVID-19 and public interest in face mask use. American Journal of Respiratory and Critical Care Medicine, 202(3), 453-455. https://doi.org/10.1164/rccm.202004-1188LE

Yancy, C. W. (2020). COVID-19 and African Americans. Journal of American Medical Association, 323(19), 1891-1892. https://doi.org/10.1001/jama.2020.6548

Yokley, J., \& Glenwick, D. S. (1984). Increasing the immunization of preschool children: An evaluation of applied community interventions. Journal of Applied Behavior Analysis, 17(3), 313-325. https://doi.org/ 10.1901/jaba.1984.17-313

Zarroli, J. (2020). The customer is always right. Except when they won't wear a mask. National Public Radio https://www.npr.org/2020/07/14/889721147/the-customer-is-always-right-except-when-they-wont-weara-mask

Zettle, R. D., \& Hayes, S. C. (1982). Rule governed behavior: A potential theoretical framework for cognitive behavior therapy. In P. C. Kendall (Ed.), Advances in cognitive behavioral research and therapy (pp. 73118). Academic. 